valuable additional contribution to some audit projects and to reviewing care plans, care programmes, etc.

All members of mental health teams need to have a degree of ownership of the scales in order to feel free to adopt them as part of their clinical practice. This will be helped by widespread use and the opportunity to comment on and thus help refine the final version. During the rest of this year the test draft of HoNOS will be freely available to anyone who wishes to contribute in this way. A conference for clinicians and managers who have been involved in the evaluation of the scales will be held in March 1995.

In addition to the clinical uses of HoNOS data, it is expected that the widespread use of these scales will be of great value in public health, resource planning and the collation of accurate and meaningful central records. At the moment, mental health indicators are restricted by the limitations of Körner data, which measure activity volumes rather than data relevant to patients' problems and outcomes.
Separate scales for users and carers are being developed and will be tested during later stages of the project.

Anyone who wishes to use the scales in their routine clinical practice is welcome to do so. We can provide a standard pack, including rating charts that can be photocopied. We would very much like specific comments to be returned to the Research Unit (please use A4 paper, headed HoNOS Comments, and include information on the setting in which the HoNOS chart was completed).

\section{Acknowledgement}

The authors wish to record their acknowledgements to Dr Gyles Glover, Department of Health, for contributing material to this article.

John Wing, Roy Curtis, and *Ann Beevor, Research Unit, Royal College of Psychiatrists, 11 Grosuenor Crescent, London SWIX 7EE

*Correspondence

\title{
Consent to medical treatment and people with learning disability
}

\author{
Jenny Curran and Sheila Hollins
}

For those people who have the cognitive and social impairments described as a learning disability, personal choice is more often than not a limited experience, (Mencap, 1989). Simple choices may be usurped by the preferences of carers, and more serious decisions may be correctly or incorrectly deemed beyond their capacity. We will address two questions which repeatedly face clinicians working with adults with learning disabilities. First, how do we ascertain a person's level of competence to give consent in relation to medical treatment? Second, in the case where a person with learning disability is considered unable to give informed consent to treatment, how do we proceed to make a decision regarding treatment?

\section{What is informed consent?}

There is a wealth of research on informed consent in different situations (King, 1986) but in this article, the focus will be on clinical aspects. Informed consent can be broken down into three necessary elements: an understanding of the basic information which is relevant to the decision about the proposed medical treatment; the capacity to make the choice; and that consent must be voluntary and free of coercion.

The basic information that needs to be understood is stated in the Code of Practice of the Mental Health Act, 1983. The patient must be able to understand why the treatment is being proposed; the nature of the proposed treatment; 
its principal benefits and risks; and the consequences of not receiving the proposed treatment.

A person with learning disability may have no difficulty with these understandings for a particular course of treatment. Learning disability of itself does not confer incapacity. Each situation must be judged individually, and be determined by the proposed treatments, as well as the person's level of cognitive functioning. For example, tooth extraction is easier to understand than amputation, and venepuncture than bone marrow transplant.

The need to understand the notion of risk, (for example, risk of significant side effects), attending on a proposed course of treatment may pose a particular difficulty for some people with learning disability, who have grasped the other main elements of information. The distinction between concrete and abstract thinking may mean that a person with learning disabilities who finds abstractions difficult is denied the opportunity to give consent. However, the doctor can choose to omit certain basic information, if it is felt to be in the patient's best interests (Hirsch \& Harris, 1988).

The second of the three elements required for informed consent is that the patient must have the capacity to exercise choice. People with learning disability may be at particular disadvantage in this respect. Often past opportunities to choose have been limited or guided by parents and teachers. A person who has had little experience of choice over relatively small day to day matters, will find a major decision regarding medical treatment more daunting than a person who has exercised choice over other life choices. Competent decision making requires practice and the freedom to learn from one's own mistakes. Learning disability services are, increasingly, acknowledging the importance of risk taking.

The third requirement is that consent must be freely given, without coercion. For a person with learning disability, used to being guided, advised and decided for, voluntariness may be difficult to assess. A common example is of a person who is heavily dependent on the approbation of others, and who tends to give the answer designed to please the questioner, particularly if the questioner is a high status figure such as a doctor. Another example is the victim of abuse, who is held in a web of emotional and physical control by the abuser, perhaps a relative, or staff member. He or she may have to rely on the abuser for many decisions, including issues of treatment.

\section{Who assesses competence?}

The assessment of incapacity is devolved to the doctor who is proposing the treatment. From a comparatively clear set of legal demands, the doctor is faced with the challenge of putting these legal elements into clinical practice. It is often the general practitioner, casualty officer or hospital specialist who has the task of determining whether a person with learning disability is able to give consent. It is likely that they will have had little training which exposed them to the particular needs of people with learning disabilities, and they may not bear in mind the local learning disability service as a source of information and support. Psychiatric specialists in learning disability can offer support and guidance to other medical colleagues in a variety of ways.

For example, in an emergency situation, the duty psychiatrist in learning disability may be called to support front-line medical staff in assessing competence out of hours. However, the local learning disability service may not provide 24 hour cover or be able to contact the physician or surgeon in time. Written statements by the learning disability psychiatrist attached to the patient's medical notes may prove helpful in guiding the physician or surgeon.

People who cannot express their informed consent are generally considered to be incapable of consenting, even though on other grounds, they are likely to satisfy the criteria for informed consent. A number of people with learning disabilities have serious communication difficulties. The ability of the assessing doctor to minimise the negative effect of communication difficulties becomes paramount. Usually, a carer or relative will accompany the patient, and offer help in clarifying the patient's communications to the doctor. However, the doctor must not rely solely on a carer's opinion or interpretation, but should make his or her own judgement. Doctors need to consider the use of informants, of signing, and other forms of augmented communication. Additionally, psychiatrists may be able to facilitate communication by attending to the dynamics of the caring system.

Crucially, the assessment of incapacity should be more widely taught both at undergraduate and postgraduate level, as a skill which doctors will need in almost every branch of medicine. Psychiatrists can help other doctors to learn skills needed for interviewing cognitively impaired patients.

\section{Choices for those who cannot choose for themselves}

It is a central legal axiom that no-one can give consent on behalf of another adult, (Bicknell, 1989). The once widespread practice of getting a relative or the ward doctor to sign a consent form' for an incompetent adult still occurs from time to time. The NHS Executive have produced 
a form to illustrate good practice in this area (NHSME, 1990).

The law has attempted to clarify how doctors are to proceed when a person cannot give consent. The most significant case concerned an adult woman who was unable to consent to sterlilisation due to her severe learning disability. This is called Re F and was heard in the House of Lords in 1989 amidst considerable controversy. It resulted in clarification of the common law relating to general medical care for adults who are unable to give consent. F was living in a mental handicap hospital and was known to be having a sexual relationship with another resident. Her carers and doctors formed the opinion that it would be in her best interests to be sterilised.

The $F$ case clarified that doctors must act in their patients' best interests. In a situation of necessity, a doctor may be considered negligent not to pursue a treatment - (usually to save life or seriously benefit the patient's health). The principles are as follows:

(a) treatment which is necessary to preserve the life, health or well being of the patient may lawfully be given without consent

(b) the standard of care required of the doctor is that he or she must act in accordance with a responsible body of relevant professional opinion

(c) in many cases it will not only be lawful to treat an incapable adult on the grounds of necessity, it will also be a common law duty, i.e. negligent to withhold treatment

(d) in the case of those mentally disordered adults who are incapable of giving consent, action properly taken may well transcend surgery or major medical treatment, and extend to include matters such as routine medical and dental treatment and even simple care such as dressing, undressing and putting to bed

(e) in practice, a decision may involve others besides the doctor. It is considered good practice to consult relatives and others who are concerned with the care of the patient, such as relevant medical specialists or the multidisciplinary team

(f) documentation in full is considered good practice in cases where the patient is incapable of giving informed consent.
Since $\operatorname{Re} F$, there has been no significant case law to alter the position described above.

\section{Comment}

This brief article has not touched on many of the wider issues of consent which the three Law Commission Reports on decision making and mentally incapacitated adults cover (Law Commission, 1993). Nor have we included discussion of the specialist problems of application of the 1983 Mental Health Act to people who are unable to give consent because of severe learning disability, as this is beyond the scope of this article (James, 1993).

People with learning disabilities remain dependent on the skills of doctors to assess their competence to give informed consent to treatment. Psychiatrists have a role to play in seeing that these skills are of the standard which people with learning disabilities deserve.

\section{References}

BickNeLL, D.J.B. (1989) Consent and people with mental handicap. British Medical Journal, 1176-1177.

HIRSCH, S.R. \& HARRIS, J. (eds) (1988) Consent and the Incompetent Pattent: ethics, law and medictne. London: Gaskell (Royal College of Psychiatrists).

JAMES, D.H. (1993) The Mental Health Acts and people with severe learning disabllity. Psychlatric Bulletin. 17. 357-358.

KnNG, J., (1986) Informed consent: a review of the empirical evidence. Institute of Medical Ethics Bulletin. Supplement 3.

LAW Commssion (1993) Mentally Incapacttated Adults and Dectsion Making. London: HMSO.

MENCAP (1989) Competency and Consent to Medical Treatment. Report of the Working Party on Legal, Medical and Ethical Issues of Mental Handicap.

NHSME (1990) A guide to consent for examination or treatment. Chapter 5: Consent by patients suffering from mental disorder. NHS Management Executive, Circular HC (90) 22.

L.J. Curran, Lecturer and Honorary Senior Registrar, Psychiatry of Learning Disability; and S.C. Hollins, Professor, Division of Psychiatry of Disability, St George's Hospital Medical School, Jenner Wing, Cranmer Terrace, London SW17 ORE

*Correspondence 